\title{
EFFECT OF FLEXIBLE ACRYLIC TO SUBSTITUTE METAL IN IMPLANT SUPPORTED REMOVABLE PARTIAL DENTURE ON ABUTMENTS CLINICAL AND RADIOGRAPHIC OUTCOME
}

\author{
Ehab A. Elsaih*
}

\begin{abstract}
Purpose: To evaluate clinically and radiographically the effect of flexible acrylic clasp and framework versus metal on abutment teeth in implant modified distal extension cases.

Methods: eighteen participants with mandibular class I partially edentulous arches modified by posterior implants opposing edentulous maxilla were allocated by simple randomization into three groups according to the removable partial denture material as follows; metal framework with RPA clasp (G1), all flexible partial denture (G2) and metal framework with flexible clasp (G3). Clinical parameters of teeth abutments with radiographic outcome of teeth/implant abutments were investigated and compared for the three groups.
\end{abstract}

Results: gingival crevice fluid volume, pocket depth and periotest values were significantly increased in all groups but comparison revealed more increase in G2 and G3. While radiographic abutment crestal bone changes were statistically significant in G1 compared to the other groups.

Distal implant did not show significant differences in marginal bone level between groups.

Conclusions: Flexible acrylic clasp challenge abutment tooth hygiene and may be a risk for future periodontitis. The traditional metal framework removable partial dentures, with RPA clasp, exceed the rest-less flexible clasp and transmit more masticatory loads to abutment teeth and in turn less preservative to surrounding alveolar bone. The hybrid design that combined a metal framework and acrylic flexible clasp and denture base may be a viable alternative when aesthetics are of primary concern and should include metal rest component.

KEY WORDS: flexible acrylic clasp, distal extension cases, implant supported, removable partial overdenture denture.

\section{INTRODUCTION}

New prosthetic materials offer opportunity to alter and/ or modify old treatment modalities as well as their biological, biomechanical and psychological outcome. When indicated, removable partial prosthesis is a classical restoration of function, esthetics and patient satisfaction despite the challenges met in hybrid support distal extension cases ${ }^{[1]}$.

* Associate Professor of Removable Prosthodontics, Department of Removable Prosthodontics, Faculty of Dentistry, Mansoura University. 
For decades the metal removable partial denture (MRPD) that consists of metal framework combined with acrylic polymers had proved long term success with acceptable function, serviceability and esthetics ${ }^{[2,3]}$.

In conditions of unilateral and/or bilateral ridge undercuts, tilted abutments, allergy to acrylic resin monomers, allergy to nickel and visibility of clasp in esthetic zone the flexible removable partial denture (FRPD) was considered an alternative modality ${ }^{[4]}$.

FRPD can resist fracture and deformity besides the capability to adapt to the shape and movement of mouth which was claimed to improve masticatory function and patient comfort ${ }^{[5,6]}$.

Metal major connector provide the required rigidity in removable partial denture (RPD) design to distribute masticatory loads evenly ${ }^{[7-9]}$. Use of flexible acrylic retainer with metal framework provides esthetics, flexibility, patient comfort and claimed to reduce stress on teeth abutments in distal extension cases ${ }^{[10,11]}$. This hybrid material prosthesis may benefits from even load distribution and load reduction on abutments. This hybrid removable partial denture (HRPD) is used by clinicians in cases of esthetic demands ${ }^{[12]}$.

For more than three decades the installation of distal implants to alter distal extension saddle cases into a modified bounded ones have attracted the attention of many researchers ${ }^{[13]}$. This addition is reported to preserve residual ridge and abutment teeth with high implant success rate and survival ${ }^{[14,15]}$.

The combined use of metal rigidity in a framework major connector and stress breaking action of flexible acrylic in a hybrid removable partial denture (HRPD) may offer a better treatment option than both MRPD and FRPD designs especially when combined with implant underneath.

This work aimed to disclose the verdict of the null hypothesis that there is no difference between effect of HRPD, MRPD and FRPD on abutment teeth, residual alveolar ridge and implants in bilateral distal extension partially edentulous cases.

\section{MATERIAL AND METHODS}

\section{Patient selection}

This work was approved by the local ethics committee, collage of dentistry, Mansoura University and according to their guide lines (A28080120).

Eighteen subjects were selected to participate in this study, the clinical characteristics of selected cases are presented in table 1. All patients had an edentulous maxillary arches and mandibular Kennedy class I partially edentulous arches. Each of them signed a formal consent states the treatment involving implant installation and clarify the schedule of follow-up.

All patients received a new temporary acrylic mandibular removable partial denture opposing complete maxillary denture. After adjustment and adaptation period of 4-6 weeks every patient had two distal implants (Superline ${ }^{\circledR}$ Dentium Co., Seoul, Korea) installed bilaterally, parallel to each other and the path of denture insertion, in the mandibular 2nd molar region. Two month later implants were revealed and the healing caps replaced by positioner abutments (Dentium Co., Seoul, Korea).

Using simple random sampling patients were divided into three groups; group $1(G 1)$ metal framework RPD (MRPD) with RPA clasp (fig. 1,a), group 2 (G2) full flexible RPD (FRPD) made of Valplast (Valpalst Int. Corp. USA) (fig. 1,b), group 3 (G3) hybrid RPD (HRPD) that consisted of metal framework with flexible retainer without metal rest (fig. 1,c).

All mandibular temporary prosthesis were replaced by permanent RPDs according to patient' group. Positioner metal sockets (Dentium Co., Seoul, Korea) were picked-up with their plastic sockets. All necessary adjustments and occlusal refinement were carried out. 
TABLE (1) Show the base line date of the selected cases according to their groups.

\begin{tabular}{|l|c|c|c|c|}
\hline \multicolumn{1}{|c|}{ Criteria } & Group 1 (MRPD) & Group 2 (FRPD) & Group 3 (HRPD) & All patients \\
\hline Gender (male/ female) & $6 / 0$ & $1 / 5$ & $4 / 2$ & $11-7$ \\
\hline Age (years) & $50.5 \pm 4$ & $50 \pm 2.5$ & $55 \pm 3$ & $52.5 \pm 4.8$ \\
\hline Previous RPDs (No.) & $1.5 \pm 0.8$ & $1.2 \pm 0.6$ & $1.2 \pm 0.2$ & $1.3 \pm 0.5$ \\
\hline Previous RPD/s (years) & $6.7 \pm 0.4$ & $5.9 \pm 0.4$ & $6.3 \pm 0.8$ & $6.3 \pm 0.5$ \\
\hline Retainer & Metal clasp (RPA) & Flexible clasp & Flexible clasp & - \\
\hline Major connector & Metal & Flexible acryl & Metal & - \\
\hline Implant attachment & Positioner & Positioner & Positioner & Positioner \\
\hline Implant length (mm) & $10-12$ & $10-12$ & 12 & $10-12$ \\
\hline Implant diameter (mm) & $3.7-4$ & $3.7-4$ & 4 & $3.7-4$ \\
\hline
\end{tabular}

Every patient had a print of the follow up schedule to be signed by the doctors in charge of follow up and assessment. Also, each had a print of clear advices in oral hygiene and use of prosthesis.

Clinical assessment for abutment teeth consisted of the flow of gingival crevice fluid (GCF), probing depth (PD) and tooth mobility (TM). For radiographic assessment, each patient had a standardized digital panoramic radiograph $(\mathrm{PN})$ and 2 standardized periapical (PA) radiographs, with butty rubber base bite stent on X-ray film holder, for abutment teeth to assess crestal bone changes (CBC) and the implant marginal bone changes (MBC).

All investigations (clinical and radiological) were done at the beginning of treatment and referred in tables as $\left(^{1}\right)$ then repeated after 18 month period of prosthesis insertion and referred in tables as $\left({ }^{2}\right)$ and the change over the study period was calculated as the difference between them and referred as $\left(^{\Delta}\right)$.

\section{Clinical parameter assessment}

An attempt to achieve a better reproducibility was made by having an experienced periodontist to examine the cases unaware of the study purpose to avoid bias.

\section{Measuring the flow of gingival crevice fluid}

The area around abutment tooth is secured dry by cotton rolls isolation and the tooth was gently air sprayed and strip of $4 \mathrm{~mm}$ wide cut Qualitative Filtration Paper (Whatman ${ }^{\circledR}$ Grade 1, GE Healthcare Europe, Freiburg, Germany) (fig. 2,a) was inserted into the gingival crevice at 3 different sites (the mid-labial surface, mid-lingual surface and distal surface) till mild resistance felt and left for 60 seconds, withdrawn, packed separately in moisture free plastic sealed tubes and kept in dry cold place till further investigations ${ }^{[16]}$.

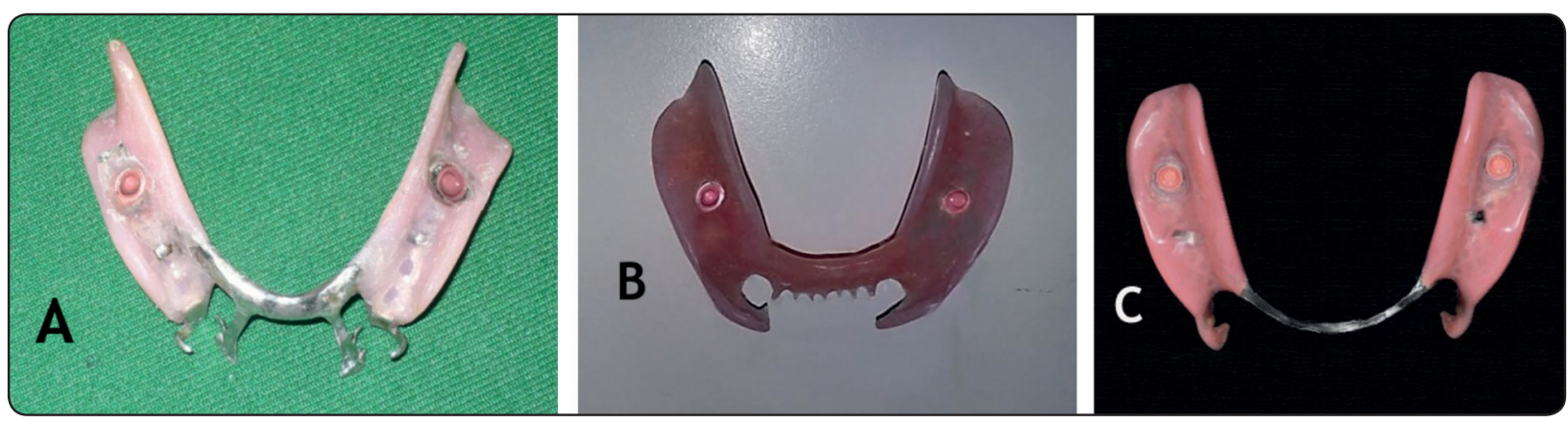

Fig. (1) a) RPD with metal framework \& metal clasp (MRPD), b) RPD with flexible framework \& flexible clasp (FRPD), c) RPD with metal framework \& flexible clasp (HRPD) 
The GCF amount in each strip was measured using micro moisture meter Periotron 8000® (Oraflow Inc. Hewlett, New York, USA). the device was calibrated before each measurement (according to manufacturer recommendation). The mean of the 3 aspects and the two sides reading was used to represent each patient.

\section{Measuring the probing depth (PD)}

Graduated periodontal probe was inserted into gingival crevice in mid-buccal and mid-lingual aspects of abutment tooth till minimal resistance is felt ${ }^{[17]}$. The mean depth in buccal and lingual aspects of right and left abutments was calculated and tabulated.

\section{Measuring the abutment teeth mobility with periotest}

Abutment tooth mobility (TM) was tested with Periotest (Periotest ${ }^{\circledR}$, Siemens AG, Bensheim, Germany) before delivery of final prosthesis and after 18 month follow-up. Measuring tip was applied buccally at each abutment three times and the average was calculated. Individual was presented as the mean of both abutments periotest value (PV).

Periotest value interpretation was done according recommended parameters (Periotest $^{\circledR}$, operating manual 2007, Eschenweg, Germany) (fig. 2, b).

\section{Radiographic measurement}

The radiologist in charge of radiographic assessments was calibrated to assure intra-examiner repeatability through measuring a number of randomly chosen $\mathrm{PA}$ and $\mathrm{PN}$ radiographs twice, with an interval of 10 days between the measurements. The intra-examiner correlation coefficient was 0.98 .

\section{Calculating abutment teeth marginal bone height changes}

Based on known actual diameter of a metal ball embedded in the rubber base bite stent attached to the x-ray holder the radiograph error is calculated to get the amount of tooth marginal bone height changes. Each PA was digitized using transparent scanner and was enlarged 5X in Corel draw program

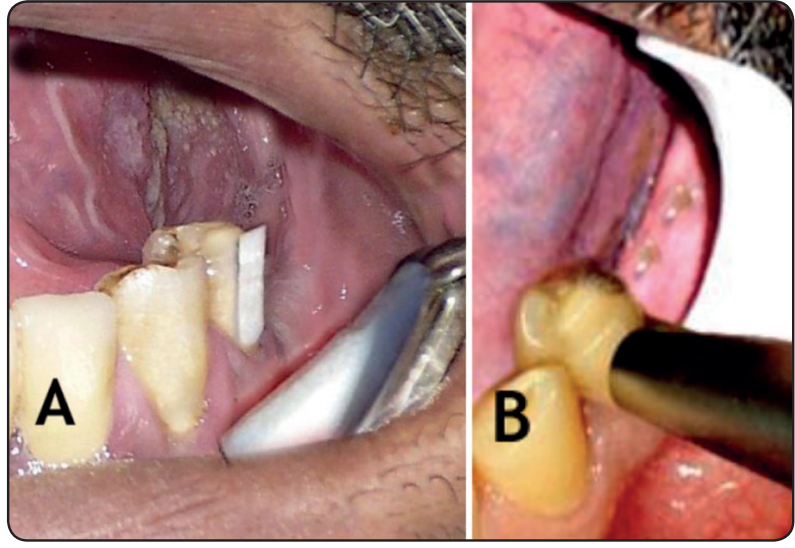

Fig. (2)) a) Qualitative Filtration Paper was inserted into the gingival crevicel, b) Periotest $(\AA$ was used to test the abutment teeth mobility. Measuring tip was applied buccally at each abutment

(CorelDraw ${ }^{\circledR}$ version 10TM, Kodak Digital Science) to measure the distance from root apex to cemento-enamel junction (CEJ) and distance from apex to alveolar bone crest $(\mathrm{ABC})$ in distal and mesial sides to calculate the mean marginal bone change $\Delta(\mathrm{CEJ}-\mathrm{ABC})$ which is referred as crestal bone changes $(\mathrm{CBC})(\text { figure } \mathbf{3}, \mathbf{a})^{[18]}$.

\section{Calculating implant marginal bone height changes}

Digital PN was enlarged 5X with focus on implant site in Corel Draw program (CorelDraw ${ }^{\circledR}$ version 10TM, Kodak Digital Science). The known actual length of (implant + abutment) and its measured length (from apex to abutment of implant) in radiograph ease calculating the magnification error (ME) at each side separately. After measuring the marginal bone height $(\mathrm{MBH})$ at the beginning of treatment and after the study period, the actual marginal bone height changes $(\mathrm{MBC})=\Delta(\mathrm{MBH}$ before- MBH after) (figure 3. b) ${ }^{[19]}$.

\section{STATISTICAL ANALYSIS}

Raw data was tabulated and processed for statistical analysis with computer program (IBM ${ }^{\circledR}$ SPSS $^{\circledast}$ 25, Statistical Package for Social Science). ANOVA with Post hoc test was used for comparison between groups and paired sample t-test was used to compare within group at $5 \%$ level of significance. 


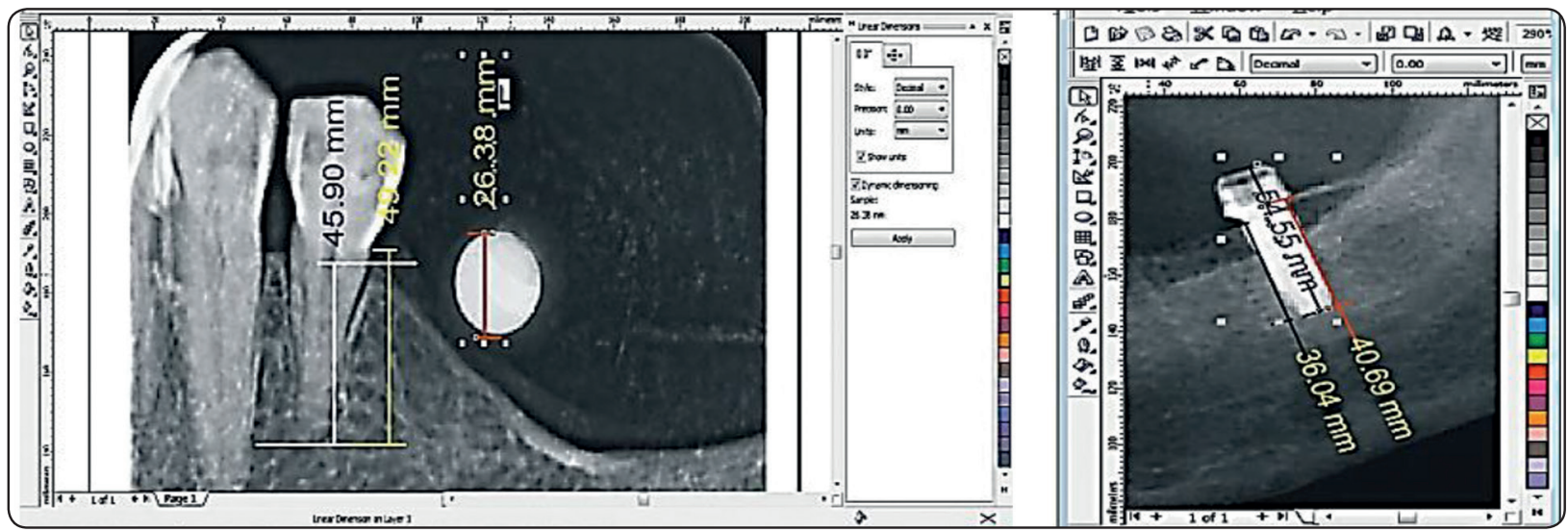

Fig. (3) a) measuring crestal bone height on abutment tooth mesially and distally, b) Measuring marginal bone height on implants.

The correlation between the mean base line reading and change over 18 months period in (GCF, PD and $\mathrm{PV}$ ) and correlation between the change in different clinical and radiographic parameters with in group was tested using Pearson correlation.

\section{RESULTS}

Comparison within group for all parameters over 18 month period revealed statistically significant changes in abutment tooth and implants.

Comparison between mean changes of all tooth clinical and radiographic parameters between groups revealed statistically significant results between $\mathrm{G} 1$ and both $\mathrm{G} 2$ and G3.
For implant radiographic outcome, comparison between all groups revealed statistically insignificant results.

There was insignificant correlation between the changes in clinical evaluation parameters (GCF, PD and PV) between base line reading and the mean changes over the study period. The correlation with in group between different parameters was as follows; in group 1 correlation was statistically significant between GCF and CBC (0.038), in group 2 correlation was statistically significant between GCF and PV (0.034).

TABLE (2) Gingival crevice fluid volume in microliters $(\mu \mathrm{L})$ at prosthesis delivery and 18 month later.

\begin{tabular}{|c|c|c|c|c|c|c|c|c|}
\hline \multirow{2}{*}{ Group } & \multirow{2}{*}{ Period } & \multirow{2}{*}{ M } & \multirow{2}{*}{ SD } & \multicolumn{2}{|r|}{ Range } & Comparison & \multirow{2}{*}{\multicolumn{2}{|c|}{$\begin{array}{l}\text { Comparison } \\
\text { between groups }\end{array}$}} \\
\hline & & & & & Max & within group & & \\
\hline \multirow{3}{*}{ G 1} & $\mathrm{GCF}^{1}$ & 44.7 & 2.2 & 41 & 48 & \multirow{2}{*}{$.000^{¥}$} & & \\
\hline & $\mathrm{GCF}^{2}$ & 71.5 & 2.8 & 65 & 75 & & & \\
\hline & $\mathrm{GCF}^{\Delta}$ & 26.7 & 3.2 & 22 & 33 & & $\begin{array}{l}\text { \# G2 } \\
\# \mathrm{G} 3\end{array}$ & $\begin{array}{l}.001^{¥} \\
.000^{¥}\end{array}$ \\
\hline \multirow{3}{*}{ G 2} & $\mathrm{GCF}^{1}$ & 51.4 & 2.2 & 49 & 57 & \multirow{2}{*}{$.000^{¥}$} & & \\
\hline & $\mathrm{GCF}^{2}$ & 73.1 & 1.5 & 71 & 75 & & & \\
\hline & $\mathrm{GCF}^{\Delta}$ & 21.7 & 3.2 & 14 & 26 & & $\begin{array}{l}\text { \# G1 } \\
\text { \# G3 }\end{array}$ & $\begin{array}{l}.001^{¥} \\
\mathrm{NS}\end{array}$ \\
\hline \multirow{3}{*}{ G 3} & $\mathrm{GCF}^{1}$ & 43.5 & 2.7 & 39 & 48 & \multirow{2}{*}{$.000^{¥}$} & & \\
\hline & $\mathrm{GCF}^{2}$ & 63.2 & 1.8 & 61 & 68 & & & \\
\hline & $\mathrm{GCF}^{\Delta}$ & 19.6 & 3.5 & 14 & 25 & & \# G1 & $.000^{¥}$ \\
\hline
\end{tabular}

$M=$ mean, $S D=$ standard deviation, $¥=$ level of significance $(\leq 0.05), N S=$ insignificant $\left({ }^{I}\right)=$ before prosthesis insertion, $\left({ }^{2}\right)=$ after prosthesis insertion, $\left(G C F^{4}\right)=\left(G C F^{1}-G C F^{2}\right),(\#)=$ in comparison to other group. 
TABLE (3) Gingival probing depth in millimeters $(\mathrm{mm})$ at prosthesis delivery and 18 month later

\begin{tabular}{|c|c|c|c|c|c|c|c|c|}
\hline \multirow{2}{*}{ Group } & \multirow{2}{*}{ Period } & \multirow{2}{*}{ M } & \multirow{2}{*}{ SD } & \multicolumn{2}{|c|}{ Range } & \multirow{2}{*}{$\begin{array}{l}\text { Comparison } \\
\text { within group }\end{array}$} & \multirow{2}{*}{\multicolumn{2}{|c|}{$\begin{array}{c}\text { Comparison between } \\
\text { groups }\end{array}$}} \\
\hline & & & & Min & Max & & & \\
\hline \multirow{3}{*}{ G 1} & $\mathrm{PD}^{1}$ & 2.3 & 0.13 & 2.1 & 2.50 & \multirow{2}{*}{$.000 ¥$} & & \\
\hline & $\mathrm{PD}^{2}$ & 2.9 & 0.21 & 2.5 & 3.30 & & & \\
\hline & $\mathrm{PD}^{\Delta}$ & 0.5 & 0.23 & 0.2 & 0.90 & & $\begin{array}{l}\# \mathrm{G} 2 \\
\# \mathrm{G} 3\end{array}$ & $\begin{array}{l}.011^{¥} \\
.000^{¥}\end{array}$ \\
\hline \multirow{3}{*}{ G 2} & $\mathrm{PD}^{1}$ & 2.3 & 0.13 & 2.1 & 2.60 & \multirow{2}{*}{$.000^{¥}$} & & \\
\hline & $\mathrm{PD}^{2}$ & 3.2 & 0.17 & 3.0 & 3.50 & & & \\
\hline & $\mathrm{PD}^{\Delta}$ & 0.8 & 0.19 & 0.6 & 1.30 & & $\begin{array}{l}\# \mathrm{G} 1 \\
\# \mathrm{G} 3\end{array}$ & $\begin{array}{l}.011^{¥} \\
\mathrm{NS}\end{array}$ \\
\hline \multirow{3}{*}{ G 3} & $\mathrm{PD}^{1}$ & 2.5 & 0.18 & 2.1 & 2.80 & \multirow{2}{*}{$.000^{¥}$} & & \\
\hline & $\mathrm{PD}^{2}$ & 3.5 & 0.18 & 3.2 & 3.90 & & & \\
\hline & $\mathrm{PD}^{\Delta}$ & 1.0 & 0.28 & 0.5 & 1.40 & & \# G1 & $.000^{¥}$ \\
\hline
\end{tabular}

TABLE (4) Abutment teeth mobility in periotest value at prosthesis delivery and 18 month later.

\begin{tabular}{|c|c|c|c|c|c|c|c|c|}
\hline \multirow[t]{2}{*}{ Group } & \multirow[t]{2}{*}{ Period } & \multirow[t]{2}{*}{$\mathrm{M}$} & \multirow[t]{2}{*}{ SD } & \multicolumn{2}{|c|}{ Range } & \multirow{2}{*}{$\begin{array}{c}\text { Comparison within } \\
\text { group }\end{array}$} & \multirow{2}{*}{\multicolumn{2}{|c|}{$\begin{array}{c}\text { Comparison } \\
\text { between groups }\end{array}$}} \\
\hline & & & & Min & $\operatorname{Max}$ & & & \\
\hline \multirow{3}{*}{ G 1} & $\mathrm{PV}^{1}$ & 3.16 & 1.40 & 1 & 6 & \multirow{2}{*}{$.000^{¥}$} & & \\
\hline & $\mathrm{PV}^{2}$ & 7.41 & 2.67 & 3 & 11 & & & \\
\hline & $\mathrm{PV}^{\Delta}$ & 4.25 & 2.66 & 0 & 8 & & $\begin{array}{l}\text { \# G2 } \\
\# \mathrm{G} 3\end{array}$ & $\begin{array}{l}.002^{¥} \\
.002^{¥}\end{array}$ \\
\hline \multirow{3}{*}{ G 2} & $\mathrm{PV}^{1}$ & 3.41 & 1.24 & 2 & 5 & \multirow{2}{*}{$.005^{¥}$} & & \\
\hline & $\mathrm{PV}^{2}$ & 5.08 & 1.31 & 3 & 8 & & & \\
\hline & $\mathrm{PV}^{\Delta}$ & 1.66 & 1.66 & 0 & 5 & & $\begin{array}{l}\text { \# G1 } \\
\text { \# G3 }\end{array}$ & $\begin{array}{l}.002^{¥} \\
\mathrm{NS}\end{array}$ \\
\hline \multirow{3}{*}{ G 3} & $\mathrm{PV}^{1}$ & 3.83 & 1.52 & 2 & 7 & \multirow{2}{*}{$.000^{¥}$} & \multirow{2}{*}{\multicolumn{2}{|c|}{ \# G1 }} \\
\hline & $\mathrm{PV}^{2}$ & 5.50 & 1.73 & 3 & 8 & & & \\
\hline & $\mathrm{PV}^{\Delta}$ & 1.66 & 0.98 & 0 & 3 & & & \\
\hline
\end{tabular}

$M=$ mean, $S D=$ standard deviation, $¥=$ level of significance $(\leq 0.05), N S=$ insignificant

$\left({ }^{1}\right)=$ before prosthesis insertion, $\left({ }^{2}\right)=$ after prosthesis insertion, $\left(P V^{4}\right)=\left(P V^{1}-P V^{2}\right)$,

(\#) =in comparison to other group. 
Table 5. Abutment teeth crestal bone changes in millimeters $(\mathrm{mm})$ over 18 month period.

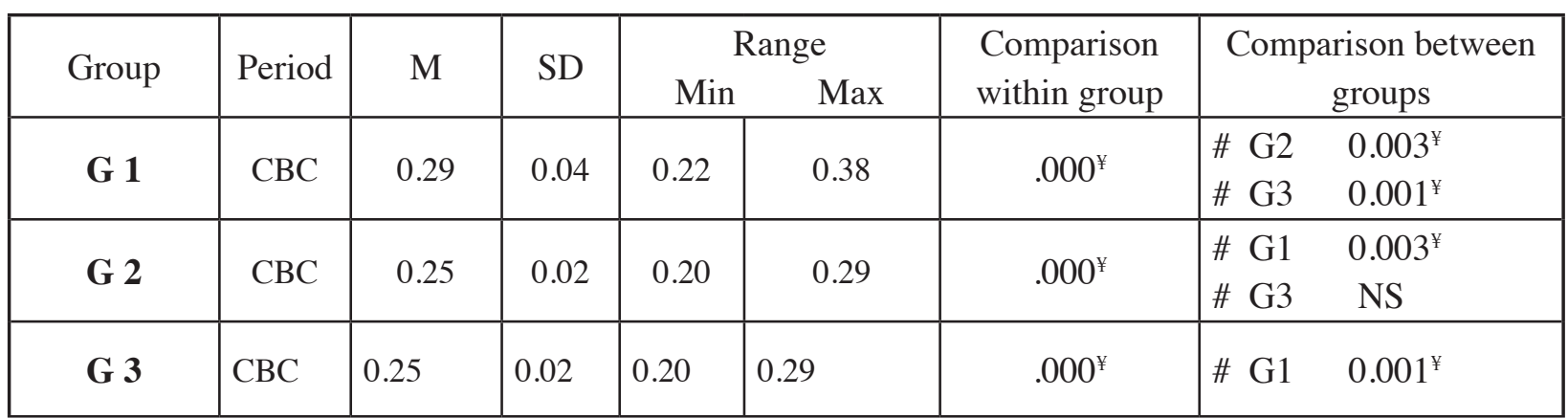

$M=$ mean, $S D=$ standard deviation, $¥=$ level of significance $(\leq 0.05), N S=$ insignificant

(\#) =in comparison to the other group

Table 6. implant marginal bone changes in millimeters ( $\mathrm{mm}$ over 18 month period.

\begin{tabular}{|c|c|c|c|c|c|c|c|c|}
\hline \multirow{2}{*}{ Group } & \multirow{2}{*}{ Period } & \multirow{2}{*}{ M } & \multirow{2}{*}{ SD } & \multicolumn{2}{|c|}{ Range } & \multirow{2}{*}{$\begin{array}{l}\text { Comparison } \\
\text { within group }\end{array}$} & \multirow{2}{*}{\multicolumn{2}{|c|}{$\begin{array}{c}\text { Comparison between } \\
\text { groups }\end{array}$}} \\
\hline & & & & & Max & & & \\
\hline \multirow{2}{*}{ G 1} & \multirow{2}{*}{$\mathrm{MBC}$} & \multirow{2}{*}{1.66} & \multirow{2}{*}{0.18} & 130 & \multirow{2}{*}{2.00} & \multirow{2}{*}{$.000^{¥}$} & \# G2 & NS \\
\hline & & & & & & & \# G3 & NS \\
\hline \multirow{2}{*}{ G 2} & \multirow{2}{*}{ MBC } & \multirow{2}{*}{1.60} & \multirow{2}{*}{0.20} & 125 & \multirow{2}{*}{2.00} & \multirow{2}{*}{$.000^{*}$} & \# G1 & NS \\
\hline & & & & 1.35 & & & \# G3 & NS \\
\hline \multirow{2}{*}{ G 3} & \multirow{2}{*}{$\mathrm{MBC}$} & \multirow{2}{*}{1.57} & \multirow{2}{*}{0.17} & 10 & \multirow{2}{*}{1.82} & \multirow{2}{*}{$.000^{¥}$} & \# G2 & NS \\
\hline & & & & 1.29 & & & \# G1 & NS \\
\hline
\end{tabular}

$M=$ mean, $S D=$ standard deviation, $¥=$ level of significance $(\leq 0.05), N S=$ insignificant

(\#) =in comparison to the other group

\section{DISCUSSION}

Implants installation can alters the classical Kennedy class I to a modified bounded saddle case. This may be helpful particularly in the mandibular arches due to decreased supporting residual alveolar ridge area and weaker teeth in comparison to maxillary arch.

The present prospective study evaluated the clinical parameters of abutment teeth and the radiographic outcome of abutment teeth/and implants to investigate the impact of the tested 3 different RPD designs on these cases over 18 months period.

Change in PD in all groups does not agree with Isidor and Budtz-Jørgensen ${ }^{[20]}$ whose observed no change in PD over 5 years RPD use.

A statistically significant decreased GCF and PD values was revealed in G1 compared to the other two groups. This may indicate a more hygienic selfcleansing design of metal clasp. Isidor and BudtzJørgensen ${ }^{[20]}$ reported reduced clinical gingival health parameters in RPD. So increase in GCF and $\mathrm{PD}$ values is related to flexible retainer design and broad coverage which render gingival margin hygiene complicated and less effective ${ }^{[21]}$. Hygiene of gingival margin is of primary significance and according to Burt $\mathrm{B}^{[22]}$ The prevention of gingivitis, in the individual patient or in populations, is still the first step toward preventing periodontitis.

Mojon , Rentsch , B`udtz-Jørgensen ${ }^{[23]}$ reported less concern of removable partial denture wearers 
had for oral health. periodontal diseases were more frequent when the restoration is defective.

Akaltan and kaynak [24] reported that with adequate checks on oral and denture hygiene at regular intervals, patients with RPDs may even experience improved periodontal health.

The broad coverage of flexible clasp may present a hygienic challenge to periodic cleaning Fueki et al ${ }^{[12]}$. This effect may be exaggerated in FRPD due to longer wearing period and sometimes continuous wearing despite advised otherwise. According to Ibraheem and Nassani ${ }^{[25]}$ the patients are motivated by light weight, ease of use and improved masticatory muscle activity.

Proper design is of same importance as proper oral hygiene to minimize abutments periodontal disease appearance ${ }^{[26,27]}$.

a statistically significant $\mathrm{CBC}$ and tooth mobility with increase PV in G1 compared to the other groups. Because there is no consensus in the literature for RPD abutment teeth $\mathrm{CBC}$, only scarce reports discussed this parameter. Results revealed small change in CBC in agreement with Isidor and BudtzJørgensen ${ }^{[19]}$. Despite significant when groups are compared the value of the change is limited when compared to reports of $\mathrm{CBC}$ ration of non-prosthetic origin. Albandar et al ${ }^{[28]}$ observed bone loss in adults over a 2 year period. For subjects from age 33 to 45 years old they observed bone loss of 0.2 $\mathrm{mm}$ per year. Also, the rate of bone loss increased with increasing initial bone loss. The small CBC, in all groups, may be attributed to the distal implants which prevents tissue-ward movement and reduce tipping force on abutment teeth.

The significance $\mathrm{CBC}$ in $\mathrm{G} 1$ is ought to less load transmitted to abutments by the cushion nature of flexible clasp in the other groups. Igarashi et al [29] reported that metal retainers transmits occlusal load that affects periodontium of abutment teeth in free end saddle. This may increase risk of abutment tooth mobility and promote crestal bone resorption. Presences of distal implant, which assist mucosal support, is thought to counteract the risk. In fact implants reduce or control rather than stop this effect and this may be promising on abutment prognostic and survival bases.

The mean MBC range in the groups 1.57-1.66mm and this agree with recorded range of $1.2-1.4 \mathrm{~mm}$ in the first year and $0.2 \mathrm{~mm}$ each year afterwards ${ }^{[30]}$.

All designs had insignificant differences in MBC around implants. This may be directly related to use of attachment with plastic insert that reduce force transmitted to implants and suggest similarity of loading patterns considering the use of the same attachment in all groups.

Apparently flexible retainer reduce load transition to abutment periodontium and decrease bone loss and PV and tooth mobility. On the other hand broad coverage present a hygiene problem that may develop a periodontal disease over longer use period. FRPD present a design mechanical defect due to absence of rigid major connector. Rigid (metal) backbone for RPD is favored to distribute and control the functional forces so that each supporting or retaining element can be used to maximum effectiveness without being stressed beyond its physiological limits ${ }^{[31]}$.

HRPD was expected to solve this defect and in same time make use of stress relief on abutment teeth caused by flexible retainer. The results did not succeed to prove superiority of hybrid design and this may be due to absence of occlusal rest. Addition of metal occlusal rest on abutment in conjunction with posterior implant attachment will create a four legged chair design which help in preserving supporting structures. As the supreme concept in RPD designs should be based on sound research data and clinical experience aimed at preserving the health of the abutment teeth and their supporting structures ${ }^{[32]}$.

Correlation coefficient of studying parameters of with in the same group revealed significant correlation, $\mathrm{P}=0.038(<0.05)$, in $\mathrm{G} 1$ between $\mathrm{GCF}$ and $\mathrm{CBC}$. Indicating a relation between volume of CGF and abutment bone resorption. The relation 
between bone remolding and increase in flow of crevice fluid was reported by Last et al ${ }^{[33]}$, Samuels et $\mathrm{al}^{[34]}$ and Alfaqeeh and Anil ${ }^{[35]}$.

Also a significant correlation, $\mathrm{P}=0.034(<0.05)$, in $\mathrm{G} 2$ between GCF and PV which may be a sign of inflammatory status rather than bone remodeling which in turn affect periodontal ligament and increase PV indicating a possible risk periodontitis. According to Taba et al ${ }^{[36]}$ and Kinney et al ${ }^{[37]}$, the flow and volume of crevice fluid increases during the inflammatory process intercellular products are created and migrate toward the gingival sulcus or periodontal pocket.

\section{CONCLUSION}

RPD effect on abutments of Kennedy class I cases is an ongoing process, controllable rather than stoppable by addition of distal implants and alteration of materials of RPD components.

Broad coverage of retainer on abutment represent an obstacle and hygienic challenge which implicate more stress on oral hygiene instruction.

It could be concluded that the increase in GCF can be used as indicator for abutment bone remolding or inflammatory based periodontitis and abutment mobility.

Occlusal loads in implant supported Kennedy class I RPD is biomechanically resisted by posterior residual alveolar ridge, implant attachment and occlusal rest.

\section{Limitation of this study}

Interpreting the results of this prospective study was reduced number of participants.

Also implementing the results to all free end cases must done with caution, especially in cases with asymmetrical abutments, pier abutments, class I modified by long anterior edentulous area and opposing arch state of edentulism or type of restoration.

\section{REFERENCES}

1. Becker CM, Kaiser DA, Goldfogel MH.Evolution of removable partial denture design. J Prosthodont. 1994; 3(3):158-66.

2. Cosme DC, Baldisserotto SM, Fernandes Ede L, Rivaldo EG, Rosing CK, Shinkai RS. Functional evaluation of oral rehabilitation with removable partial dentures after five years. J Appl Oral Sci. 2006;14(2):111-6.

3. Dula LJ, Ahmedi EF, Lila-Krasniqi ZD, Shala KSh. Clinical evaluation of removable partial dentures on the periodontal health of abutment teeth: a retrospective study. Open Dent J. 2015;9:132-9.

4. Shamnur SN, Jagdish KN, Kalavathi K. Flexible DenturesAn alternate for rigid dentures. J Dent Sci \& Res. 2010; 1: 74-9.

5. Sharma A, Shashidhara HS. A review: Flexible removable partial dentures. J Dent Med Sci \& Res. 2014; 13: 58-62.

6. Singh JP1, Dhiman RK, Bedi RP, Girish SH. Flexible denture base material: A viable alternative to conventional acrylic denture base material. Contemp Clin Dent. 2011;2(4):313-7.

7. Phoenix RD, Cagna DR, DeFreest CF. Stewart's clinical removable partial prosthodontics Chicago: Quintessence. 2003; pp. 53-102.

8. Daher T, Hall D, Goodacre CJ. Designing successful removable partial dentures. Compend Contin Educ Dent. 2006;27(3):186-93.

9. Singh K, Aeran H, Kumar N, Gupta N. Flexible thermoplastic denture base materials for aesthetical removable partial denture framework. J Clin Diagn Res. 2013 Oct;7(10):2372-3.

10. Taleb FAA, Eltorky IR, El-Sheikh MM, Moula SA. Patient Satisfaction and Radiographyical Evaluation of Acetal Resin Retentive Clasp Arm versus Conventional Clasp on Abutment Teeth in Upper Unilateral Removable Partial Dentures. J Am Sci, 2013; 5(9):425-31.

11. Mohamed T, Baraka OA, Badawy MM, Comparison between Acetal Resin and Cobalt-chromium Removable Partial Denture Clasps: Effect on Abutment Teeth Supporting Structures, Intl. J Prostho \& Restor Dent. 2011;1(3):147-54.

12. Fueki K, Ohkubo C, Yatabe M, Arakawa I, Arita M, Ino S, Kanamori T, Kawai Y, Kawara M, Komiyama O, Suzuki T, Nagata K, Hosoki M, Masumi S, Yamauchi M, Aita H, Ono T, Kondo H, Tamaki K, Matsuka Y, Tsukasaki H, Fujisawa M, Baba K, Koyano K, Yatani H. Clinical application of removable partial dentures using thermoplastic resin-part I: definition and indication of non-metal clasp dentures. J Prosthodont Res. 2014 Jan;58(1):3-10. 
13. De Freitas RF, de Carvalho Dias K, da Fonte Porto Carreiro A, Barbosa GA, Ferreira MA. Mandibular implant-supported removable partial denture with distal extension: a systematic review. J Oral Rehabil. 2012 Oct;39(10):791-8.

14. Omran AOM, Fouad MM, Elsyad MA. Effect of different attachments designs used for implant assisted mandibular distal extension RPD. An in vitro study of stresses transmitted to abutment teeth. Mansoura Journal of Dentistry 2014;1(3):124-130.

15. Mitrani R, Brudvik JS, Phillips KM. Posterior implants for distal extension removable prostheses: a retrospective study. Int J Periodontics Restorative Dent. 2003;23(4):353-9.

16. Lamster IB, Hartley LJ, Vogel RI. Development of a biochemical profile for gingival crevicular fluid. Methodological considerations and evaluation of collagen-degrading and ground substance-degrading enzyme activity during experimental gingivitis. J Periodontol. 1985 Nov;56(11 Suppl): 13-21.

17. Loe H, Silness J. Periodontal disease in pregnancy. i. prevalence and severity. acta odontol scand. 1963;21:533-51.

18. Schei, O, Waerhaug, J, Lovdal, A, Arno, A. Alveolar bone loss as related to oral hygiene and age. J Periodontol. 1959;30:7-16.

19. Lee KJ, Kim YG, Park JW, Lee JM, Suh JY. Influence of crown-to-implant ratio on periimplant marginal bone loss in the posterior region: a five-year retrospective study. J Periodontal Implant Sci. 2012 Dec;42(6):231-6.

20. Isidor F, Budtz-Jørgensen E. Periodontal conditions following treatment with distally extending cantilever bridges or removable partial dentures in elderly patients. A 5-year study. J Periodontol. 1990;61(1):21-6.

21. Berg E. Periodontal problems associated with use of distal extension removable partial dentures--a matter of construction? J Oral Rehabil. 1985 Sep;12(5):369-79.

22. Burt B; Research, Science and Therapy Committee of the American Academy of Periodontology. Position paper: epidemiology of periodontal diseases. J Periodontol. 2005;76(8):1406-19.

23. Mojon P, Rentsch A, Budtz-Jørgensen E. Relationship between prosthodontic status, caries, and periodontal disease in a geriatric population. Int J Prosthodont. 1995 Nov-Dec; 8(6):564-71.

24. Akaltan F, Kaynak D. An evaluation of the effects of two distal extension removable partial denture designs on tooth stabilization and periodontal health. J Oral Rehabil. 2005;32(11):823-9.
25. Ibraheem EM, Nassani MZ. The effect of flexible acrylic resin on masticatory muscle activity in implant-supported mandibular overdentures: a controlled clinical trial. Electron Physician. 2016 Jan 15;8(1):1752-8.

26. Zlatarić DK, Celebić A, Valentić-Peruzović M. The effect of removable partial dentures on periodontal health of abutment and non-abutment teeth. J Periodontol. 2002 Feb; 73(2): 137-44.

27. Merijohn GK. Management and prevention of gingival recession. Periodontol 2000. 2016;71(1):228-42.

28. Albandar JM, Rise J, Gjermo P, Johansen JR. Radiographic quantification of alveolar bone level changes. A 2-year longitudinal study in man. J Clin Periodontol. 1986;13(3):195200.

29. Igarashi Y, Ogata A, Kuroiwa A, Wang CH. Stress distribution and abutment tooth mobility of distal-extension removable partial dentures with different retainers: an in vivo study. J Oral Rehabil. 1999;26(2):111-6.

30. Snauwaert K, Duyck J, van Steenberghe D, Quirynen M, Naert I. Time dependent failure rate and marginal bone loss of implant supported prostheses: a 15-year follow-up study. Clin Oral Investig. 2000;4(1):13-20.

31. Lyons KM1, Beumer J 3rd, Caputo AA. Abutment load transfer by removable partial denture obturator frameworks in different acquired maxillary defects. J Prosthet Dent. 2005;94(3):281-8.

32. Schwartzman B, Caputo A, Beumer J. Occlusal force transfer by removable partial denture designs for a radical maxillectomy. J Prosthet Dent. 1985 Sep;54(3):397-403.

33. Last KS, Donkin C, Embery G. Glycosaminoglycans in human gingival crevicular fluid during orthodontic movement. Arch Oral Biol. 1988;33(12):907-12.

34. Samuels RH1, Pender N, Last KS. The effects of orthodontic tooth movement on the glycosaminoglycan components of gingival crevicular fluid. J Clin Periodontol. 1993 May;20(5):371-7.

35. Alfaqeeh SA, Anil S. Gingival crevicular fluid flow rate and alkaline phosphatase level as potential marker of active tooth movement. Oral Health Dent Manag. 2014 Jun; 13(2): 458-63.

36. Taba M Jr, Kinney J, Kim AS, Giannobile WV. Diagnostic biomarkers for oral and periodontal diseases. Dent Clin North Am. 2005;49(3):551-71.

37. Kinney JS, Ramseier CA, Giannobile WV. Oral fluid-based biomarkers of alveolar bone loss in periodontitis. Ann N Y Acad Sci. 2007 Mar;1098:230-51. 